\title{
Locomotor Basic Movement Levels in Improving the Health of Elementary School Students
}

\author{
Eka Fitri Novita Sari ${ }^{1, *}$, Rekha Ratri Julianti ${ }^{2}$, Nofi Marlina Siregar ${ }^{1}$, Sukiri $^{1}$ \\ ${ }^{1}$ Department of Physical Education, Universitas Negeri Jakarta, Jln Pemuda 10 Rawamangun Jakarta Timur, Indonesia \\ ${ }^{2}$ Department of Physical Education, Universitas Singaperbangsa Karawang, Jl. H.S. Ronggowaluyo Telukjambe Timur Karawang \\ Barat Jawa Barat, Indonesia
}

Received September 22, 2020; Revised November 26, 2020; Accepted December 22, 2020

\section{Cite This Paper in the following Citation Styles}

(a): [1] Eka Fitri Novita Sari, Rekha Ratri Julianti, Nofi Marlina Siregar, Sukiri, "Locomotor Basic Movement Levels in Improving the Health of Elementary School Students, "International Journal of Human Movement and Sports Sciences, Vol. 8, No. 6A, pp. 16-21, 2020. DOI: 10.13189/saj.2020.080703.

(b): Eka Fitri Novita Sari, Rekha Ratri Julianti, Nofi Marlina Siregar, Sukiri (2020). Locomotor Basic Movement Levels in Improving the Health of Elementary School Students. International Journal of Human Movement and Sports Sciences, 8(6A), 16-21. DOI: 10.13189/saj.2020.080703.

Copyright $\odot 2020$ by authors, all rights reserved. Authors agree that this article remains permanently open access under the terms of the Creative Commons Attribution License 4.0 International License

\begin{abstract}
Children's health could be monitored through basic motion skills, for example, running, walking, jumping, sliding, galloping, skipping, hopping, and leaping. Children could be determined as healthy if they can perform those movements properly aligning with their development phase. This study is a part of research development in order to develop test instruments of basic locomotor skills through puzzle-based activity. This study aims to describe elementary school students' health levels through 8 basic locomotor skills measured by the test instruments. The data were collected through a descriptive approach. The participants consisted of 60 students in a class, Ciracas, East Jakarta. The study shows that 35 students $(58,33 \%)$ received a good score in walking, 29 students $(48,33 \%)$ received a good score in running, while 38 students received a good score in jumping, hopping, leaping, galloping, skipping, and sliding. According to the results, students' health levels in this study varied as 25 students (42\%) received overall good scores, 20 students (33\%) received overall average scores, while 15 students (25\%) received an overall bad score.
\end{abstract}

Keywords Locomotor Movement, Elementary Students, Physical Activity

\section{Introduction}

Physical activities are more favourable from the perspective of 7 to 8 years old first-grade elementary school students. Carson et al., Johnstone, Hughes, Martin, \& Reilly (2018) described that children who are involved in frequent physical activities could be benefited from their health. To be precise, frequent physical activities may reduce the risk of cancer, depression, diabetes, and prevent obesity. It also enhances students' cognitive development, develops healthy bones, psychosocial, and cardiometabolic [1, 2]. Healthy and active lifestyles during the early stages of childhood will help improve their motor development throughout the growing process [3]. Physical activities that could be conducted by children are various, for example, active play.

Johnstone, Hughes, Bonnar, Booth, \& Reilly described that the approach of active play could address the low rate of physical activity and enhance students' basic motion skills [4]. Westlund Stewart, Divine, O, \& Law also described that Task Force on Community Preventive Services is recommended to schools that incorporate it has managed to enhance students' physical activity through modification of social circle and behaviour [5]. Increasing the number of physical activity areas in playgrounds in school and after school play an important role in children's physical activity habits [6] Thus, the approach of active playing should be considered and incorporated by physical education teachers in schools.

The basic locomotor motion is the movement of the body from one place to another where it becomes the teaching material for physical education teachers in grade 
one elementary school. Through basic locomotor movements, students will explore their ability to move. This activity is one of the structured physical activities that students can do at school.

M Dipa, Sari \& M. Mashur (2018), Pratiwi et al (2019), Sari Sujarwo \& Sukiri (2020) described their study results that active play could be incorporated through games which enhance students' basic motion skills. Also, the teachers could modify the medium of learning in schools during active play [7]-[9]. Active play motivates the students to actively participate during physical education class through designing a fun learning activity with appropriate assessment instruments to measure students' development in the elementary school level that could provide meaningful learning activity for the students.

Basic locomotor skills in the education context are supplementary activity incorporated by PE teachers in order to reach goals based on the elementary school curriculum. It consists of students' movement which moves from one spot to another spot, for example, walking, jumping, sliding, hopping, galloping, skipping, and leaping. These movements are also determined as part of active physical play that enhances students' body function in order to achieve proficiency in conducting various basic motion skills which contribute to enhanced body health.

The problem that exists is how to achieve the basic locomotor motion of first-grade elementary school students. Whether the teacher has maximized the process of teaching activities to reach the achievement of learning outcomes for locomotor basic motion is well illustrated. This portrait is needed in which through the data obtained, the quality of the physical activity can be described.

Wibowo, Nugroho, \& Sultoni (2018) described their study results in examining the correlation between fundamental movement skills (FMS) and games performance of elementary students in modified invasion game activities, the results show that there are significant correlations between the two variables [10]. Capio, Sit, Eguaia, Abernethy, \& Masters (2015) described that FMS is able to influence children's physical activity (PA) and children who are influenced showed a tendency to be more active in learning [11]. Ng \& Button (2018) conducted a meta-analysis study which described positive correlations between PA, FMS, MVPA, and TPA during childhood [12]. D. Jones, A. Innerd, E. Giles et al (2020) also shared similar results with the previous studies which described the positive correlation between PA and FMS during childhood [13].

The previous studies have shown that generally, proficiency in basic motion skills have a positive influence on physical activities through active play activities which could be structured or flexible play, and teachers could also modify tools and medium of learning to enhance students' happiness during learning through social circle intervention. The efforts will make students more active in learning in the long-term, thus developing students' fundamental movement skills.

This research was conducted to capture the achievement of basic locomotor movements of first grade elementary school students where through these activities it is expected that the achievement of physical activity of first grade primary school students can also be illustrated.

\section{Materials and Methods}

Research development has been studying basic locomotor motions level in improving the health of elementary school students through developing instruments to measure students' basic locomotor skills which incorporate puzzle-based activity. The aim of this study is to describe elementary school students' health achievement through measurement instruments.

This study incorporated descriptive quantitative as its methodology design through tests in which a series of data were collected. The participants of this study consist of 60 elementary school students in one class. The samples were about 8-9 years old with an average weight of $26-29 \mathrm{~kg}$ and an average height of $128-134 \mathrm{~cm}$. The school is located in Ciracas, East Jakarta. The test instrument of basic locomotor skills is based on a puzzle game that was incorporated to observe 8 basic locomotor skills which consist of walking, running, jumping, sliding, leaping, galloping, skipping, and hopping [5, 12, 13].

\section{Operational Definition}

Students' health level was determined through physical activity achievement by conducting the basic pattern of locomotor skills which consist of running, walking, jumping, galloping, sliding, hopping, leaping, and skipping with puzzle-based activity approach.

\section{Conceptual Definition}

Students' health level is overall physical activity in the form of 8 basic locomotor skills which are conducted through puzzle-based activity. The students were measured based on their maximum and minimum score. The dimension of basic locomotor skills consists of 4 indicators which are head, body, arms, and limbs. If all 4 indicators are conducted successfully, the students will receive an overall score of 4 . To be precise, the formula of measuring students' score is described as below:

$$
\text { Overall Score }=\frac{\text { Score Received } \times 100 \%}{\text { Total Score }}
$$

The following table 1 is a locomotor basic movement research instrument for first grade students which were developed with eight locomotor basics. 
Table 1. Locomotor Basic Movement Skills Instruments for First Grade Students

\begin{tabular}{|c|c|c|}
\hline Skills & Indicators & Description \\
\hline Walk & \multirow{8}{*}{$\begin{array}{l}\text { Head } \\
\text { Body } \\
\text { Arms } \\
\text { Legs }\end{array}$} & $\begin{array}{l}\text { The eyes view are straight forward, the } \\
\text { hands are swinging back and forth, the } \\
\text { body position is upright, and the foots } \\
\text { move forward alternately }\end{array}$ \\
\hline Run & & $\begin{array}{l}\text { Straight forward view, relaxed body } \\
\text { position and leaning forward, hands } \\
\text { swing back and forth alternately, knee } \\
\text { position raised with both feet moved } \\
\text { quickly and flying towards to the front }\end{array}$ \\
\hline Slide & & $\begin{array}{l}\text { The body moves sideways, the eyes look } \\
\text { horizontally, the arms move following } \\
\text { the movement of the body, and the legs } \\
\text { are not crossed. }\end{array}$ \\
\hline Leap & & $\begin{array}{l}\text { Both legs are raised, moving forward } \\
\text { alternately for several steps and then } \\
\text { jumping and preceded landing on one } \\
\text { leg, swinging hands following body } \\
\text { movements, straight eyesight. }\end{array}$ \\
\hline Gallop & & $\begin{array}{l}\text { A straight forward view, the position of } \\
\text { the foot is lifted alternately and moves } \\
\text { forward, relaxing body, the position of } \\
\text { the hand follows body movements. }\end{array}$ \\
\hline Skip & & $\begin{array}{l}\text { The feet jump alternately (up and down), } \\
\text { the position of the body upright moves to } \\
\text { float, a straight forward view, the hand } \\
\text { swings following the body movements. }\end{array}$ \\
\hline Hop & & $\begin{array}{l}\text { One of the legs is lifted up alternately } \\
\text { and moves forward, one hand straight up } \\
\text { opposite the leg raised up, body position } \\
\text { is upright, and when landing begins with } \\
\text { one leg as a pedestal }\end{array}$ \\
\hline Jump & & $\begin{array}{l}\text { The position of the body is lifted and } \\
\text { moves from one place to another place, } \\
\text { hands are swinging forward following } \\
\text { body movements, feet are raised forward } \\
\text { (down and up) quickly, knees are bent } \\
\text { when landing. }\end{array}$ \\
\hline
\end{tabular}

\section{Results and Discussion}

The Data on test results in this study are presented in two parts. These are the average scores for each locomotor base motion item and the average score for the whole basic motion item. The distribution result data is presented to determine the level of student ability in each test item and also the overall motion variable in first-grade students in elementary school.

The data is obtained from the basic motion test on 60 students of the first-grade elementary school in the Ciracas area of East Jakarta which the site was possible for the researchers in conducting this data collection. Following are the data obtained on each basic motion item.
Table 2. Number of Students Based on Locomotor Basic Motion Tests per Item

\begin{tabular}{|c|c|c|c|c|}
\hline \multirow{2}{*}{ No } & \multirow{2}{*}{ Items } & \multicolumn{3}{|c|}{ Student Total } \\
\hline & & Good & Medium & Less \\
\hline 1. & Walking & 35 & 24 & 1 \\
\hline 2. & Running & 29 & 27 & 4 \\
\hline 3. & Jumping & \multirow{6}{*}{14} & \multirow{6}{*}{38} & \multirow{6}{*}{8} \\
\hline 4. & Sliding & & & \\
\hline 5. & Hopping & & & \\
\hline 6. & Galloping & & & \\
\hline 7. & Skipping & & & \\
\hline 8. & Leaping & & & \\
\hline
\end{tabular}

Table 3. Percentage Obtained from the Locomotor Basic Motion Test per Item

\begin{tabular}{|c|c|c|c|c|}
\hline \multirow{2}{*}{ No } & \multirow{2}{*}{ Items } & \multicolumn{3}{|c|}{ Percentage (\%) } \\
\cline { 3 - 5 } & & Good & Medium & Less \\
\hline 1. & Walking & 58,33 & 40 & 1,67 \\
\hline 2. & Running & 48,33 & 45 & 6,67 \\
\hline 3. & Jumping & & & \\
\hline 4. & Sliding & & & \\
\hline 5. & Hopping & \multirow{2}{*}{23,33} & 63,33 & 13,33 \\
\hline 6. & Galloping & & & \\
\hline 7. & Skipping & & & \\
\hline 8. & Leaping & & & \\
\hline
\end{tabular}

From the data table 2 and table 3 , it was found that the eight basic locomotor motions of the students on each test item showed varying gains. From the eight basic movements, six items namely jumping, sliding, hopping, galloping, skipping, and leaping, illustrate the acquisition of the medium category, an average of 60 students there are 38 in the moderate category or around $63.33 \%$ and the acquisition of good categories only 14 students or around $23.33 \%$ and fewer categories as many as 8 students with a percentage of around $13.33 \%$ (see table $2 \& 3$ ). While the two locomotor basic motion items, namely walking and jumping, illustrate better gains because the number of students in the good category reached more than the six other items. Walking based on good categories illustrated as many as 35 students (58.33\%) and running 29 students $(48.33 \%)$ while based on the medium categories being drawn walking 24 students (40\%) and running 27 students $(45 \%)$, and based on the less categories with a very small number were walking 1 student (1.67\%) and running 4 students $(6.67 \%)$ (see table 2 and 3 ).

Distribution of further research data is presented in the form of an average of all locomotor basic motion variables, through which this data will illustrate eight overall levels of student ability. The following picture 1 is the presented data. 


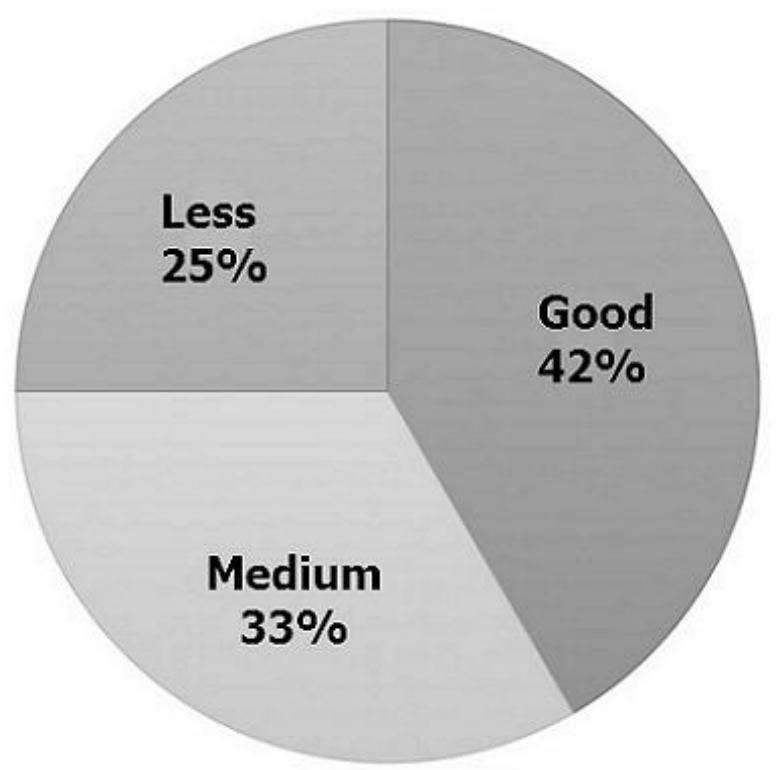

\section{Less Good Medium}

Picture 1. Number of Students and Percentage Level of Locomotor Basic Motion Abilities Based on Overall Locomotor Basic Motion Items

Yusamawati et. al., 2019 states that learning outcomes obtained by students in locomotor basic motion material are influenced by many factors including student input, teacher quality, school support [16]. Ivan Serbetar states that for optimal perceptual-motor development, stimulating home environment should be accompanied by enjoyable play and exercise facilities and surroundings, which should be accessible, well structured, and should increase children's opportunity to be physical active and to develop motor skills [17]. Eka Sari, 2014 explained the results of her research that parenting for children in active play activities at primary school age affects the basic ability of children at that age [18]. According to Logan and Hardy in Wesley O'brien, it is important to note that these basic movement patterns are not naturally acquired during the process of maturation, movement practitioners need to structure and implement developmentally appropriate activities, specific teaching and learning (with feedback) during physical education with continuous provision for opportunities of practice available [19].

Based on the statement above and the data obtained in the study, many factors and elements underlie a child's basic mobility. When the ability is good or even lacking, we can evaluate some of the factors behind it. The role of the teacher in the school is a role that is no less important than the role of family and parents in terms of laying the foundation and developing basic mobility. Physical education teachers in primary schools are an important element in the implementation of formal activities.

Caint C. T. Clark et. al., 2016 states that fundamental movement skills are considered as the basic building blocks for movement and provide the basis for special movement and sports skills needed to participate in various physical activities [20]. J Lee, T. Zhang, T. Chu et al., conducted a study to examine the effects of an 8-week FMS-based afterschool program on physical and cognitive health outcomes among children. This finding suggests that structured FMS-Focused strategies (e.g., fun games and goal settings) can be a critical component when implementing a physical activity program to enhance children's motor skills and physical activity behaviour [21].

Through a variety of fun activities both in formal and informal activities, the child will do basic movement activities without feeling bored and unmotivated. Moving for a long time though is not a fundamental problem for them. Sebire Simon, R. Jago, K. Fox et al., 2013, in their research results stated that children's motivation to consciously move in physical activity is based on their satisfaction and pleasure while doing the activity [22]. Based on these psychological factors, students take pleasure in physical activity which provides the positive motivation that can be a potential target of physical education teachers in the framework of designing, implementing and even evaluating student learning activities in elementary school. Active student involvement in physical activity through locomotor basic motion was done with a condition of awareness that these activities can motivate them to carry out with sufficient time setting and a set of appropriate strategies; the problems related to health are things that might not happen.

Based on data from research on several existing samples, it is illustrated that the results of the locomotor basic motion of first grade elementary school students in the Ciracas area are in the good category (picture 1) where the number of samples shows a higher number with $42 \%$ students. Through these results it can also be described in general that students have good physical activity. Gralla, McDonald, et. al., 2019 wrote that physical activity in youth can produce greater health benefits than average or low activity as evidenced by the results of research he has done [23]. L. Bolger, Linda A., et. al., 2019 in his research to investigate the correlation between fundamental movement skills and signs of health of elementary school children in Ireland resulted in the conclusion that various types of FMS are important for the cardiorespiratory fitness of physical activity (PA) children [24].

The results obtained from this study related to the locomotor basic motion of 60 first-grade elementary school students in the Ciracas area of East Jakarta illustrates how the achievement of locomotor basic motion skills and expectations also on their health level. Students who move actively with good locomotor basic motion results give a temporary picture that they are healthy because they can move actively by displaying their abilities through these activities. To measure more deeply the level of health caused by locomotor basic motion activities, in terms of the capacity of bodily functions, 
whether it is proven that good results are also needed, a deeper study and collaboration with researchers who have the capacity in diagnosing and measure their health levels in depth.

\section{Conclusions}

Based on the results of the study it was concluded that the level of locomotor basic mobility ability of 60 first-grade elementary school students in the Ciracas area of East Jakarta was in a good category as seen from the number of students who were in the three categories compiled showing a greater number with 25 students $(42 \%)$, and students who are in the medium category with a total of $20(33 \%)$ and only 15 students $(25 \%)$ are in the poor category. Based on these results a special study needs to be undertaken in collaboration with pediatric sports researchers whether with the level of physical activity through locomotor basic motion the student's health function and capacity are validly proven in the study.

\section{Acknowledgments}

We would like to show great gratitude to the physical education teacher and first-grade students in the East Jakarta Ciracas area who gave us our time and opportunity to conduct research.

\section{REFERENCES}

[1] A. Johnstone, A. R. Hughes, A. Martin, and J. J. Reilly, "Utilising active play interventions to promote physical activity and improve fundamental movement skills in children: A systematic review and meta-analysis," $B M C$ Public Health, vol. 18, no. 1, pp. 1-13, 2018.

[2] V. Carson et al., "Systematic review of the relationships between physical activity and health indicators in the early years (0-4 years)," BMC Public Health, vol. 17, no. Suppl 5, 2017.

[3] N. A. A. Roslan and B. Abdullah, "Differences in the level of children gross motor skills development in silat, taekwondo and karate in malaysia," International Journal of Human Movement and Sports Sciences, vol. 8, no. 2, pp. 5762,2020

[4] A. Johnstone, A. R. Hughes, L. Bonnar, J. N. Booth, and J. J. Reilly, "An active play intervention to improve physical activity and fundamental movement skills in children of low socio-economic status: feasibility cluster randomised controlled trial," Pilot Feasibility Stud., vol. 5, no. 1, p. 45, Dec. 2019.

[5] N. Westlund Stewart, A. Divine, J. O, and B. Law,
"Considerations for Conducting Imagery Interventions in Physical Education Settings," J. Imag. Res. Sport Phys. Act., vol. 10, no. 1, Jan. 2015.

[6] H. Çolak, "The impact of daily habits on the physical activity levels of children aged 7-10: An investigation," Universal Journal of Educational Research, vol. 7, no. 1, pp. 118-125, 2019.

[7] E. F. N. Sari, Sujarwo, and Sukiri, "The Improvement of Locomotor Basic Movement Through AniChrac Games," 2020.

[8] J. P. Jasmani et al., "Improving The Basic Movement Learning Outcomes Through Modification Of Learning Media In Grade V,” no. 01, pp. 25-33, 2019.

[9] J. P. Jasmani and D. A. N. Adaptif, "The Learning Model Of Basic Motion Jump Based Rainbow,” no. 02, pp. 46-50, 2018.

[10] R. Wibowo, E. Nugraha, and K. Sultoni, "Fundamental Movement Skills and Game Performance in Invasion Game Activities," no. January 2019, pp. 390-395, 2018.

[11] J. Yu, C. H. P. Sit, C. M. Capio, A. Burnett, A. S. C. Ha, and W. Y. J. Huang, "Fundamental movement skills proficiency in children with developmental coordination disorder: Does physical self-concept matter?," Disabil. Rehabil., 2016.

[12] J. L. Ng and C. Button, "Reconsidering the fundamental movement skills construct: Implications for assessment," Mov. Sport Sci. - Sci. Mot., no. 102, pp. 19-29, 2018.

[13] D. Jones, A. Innerd, E. L. Giles, and L. B. Azevedo, "Association between fundamental motor skills and physical activity in the early years: A systematic review and meta-analysis," Journal of Sport and Health Science. Mar-2020.

[14] E. F. N. Sari, Sujarwo, and S. Sukiri, "Basic Locomotor Movement of First Grade Students of Elementary School BT - 5th International Conference on Physical Education, Sport, and Health (ACPES 19),” 2019.

[15] E. F. N. Sari, "Locomotor basic movement skill instruments through games for elementary school," J. Phys. Conf. Ser., vol. 1402, p. 077081, Dec. 2019.

[16] Yusmawati, Y. Yusmawati, and E. F. N. Sari, "The Implementation of Basic Locomotor Learning in Special Schools BT - 5th International Conference on Physical Education, Sport, and Health (ACPES 19)," 2019.

[17] I. Serbetar, J. M. Loftesnes, and I. Prprovic, "Disparities in Motor Competence between Roma and Non-Roma Children in Croatia and Relations of Motor Competence, School Success and Social Economic Status," vol. 7, no. 2, pp. 1924, 2019.

[18] E. F. N. Sari, "Parenting and fundamental movement skills," Asian Soc. Sci., vol. 10, no. 5, pp. 22-27, 2014.

[19] W. O' Brien, S. Belton, and J. Issartel, "Fundamental movement skill proficiency amongst adolescent youth," Phys. Educ. Sport Pedagog., vol. 21, no. 6, pp. 557-571, Nov. 2016.

[20] C. C. T. Clark, C. M. Barnes, M. Holton, H. D. Summers, 
and G. Stratton, "A Kinematic Analysis of Fundamental Movement Skills," Sport Sci. Rev., vol. 25, no. 3-4, pp. 261275,2016

[21] J. Lee, T. Zhang, T. L. (Alan) Chu, X. Gu, and P. Zhu, "Effects of a Fundamental Motor Skill-Based Afterschool Program on Children's Physical and Cognitive Health Outcomes," Int. J. Environ. Res. Public Health, vol. 17, no. 3, p. 733, Jan. 2020.

[22] S. J. Sebire, R. Jago, K. R. Fox, M. J. Edwards, and J. L. Thompson, "Testing a self-determination theory model of children's physical activity motivation: a cross-sectional study," Int. J. Behav. Nutr. Phys. Act., vol. 10, no. 1, p. 111, 2013.

[23] M. H. Gralla, S. M. McDonald, C. Breneman, M. W. Beets, and J. B. Moore, "Associations of Objectively Measured Vigorous Physical Activity With Body Composition, Cardiorespiratory Fitness, and Cardiometabolic Health in Youth: A Review," Am. J. Lifestyle Med., 2019.

[24] L. A. Bolger et al., "Fundamental Movement Skill Proficiency and Health Among a Cohort of Irish Primary School Children," Res. Q. Exerc. Sport, vol. 90, no. 1, pp. 24-35, Jan. 2019. 